\title{
Numerical Study of the Thermal Model on High Uniformity Temperature Test Platform
}

\author{
Zijuan Wang ${ }^{1}$, Ying Zhou ${ }^{1}$, Xiao Han ${ }^{1,2}$ and Jingyi Shao ${ }^{1}$ \\ ${ }^{1}$ Beijing Institute of Spacecraft Environment Engineering, Beijing 100094, China \\ ${ }^{2}$ School of Astronautics, Beihang University, Beijing 100191, China
}

\begin{abstract}
The surface temperature uniformity of a test platform with an effective test area of $600 \mathrm{~mm} \times$ $600 \mathrm{~mm}$ was numerically studied. The conductive heat transfer model for the test platform and the device under test (DUT) installed on the surface was established in the present work, as well as the radiation heat transfer model from the platform surface to the background temperature. The platform surface was divided into 5 or 9 regions where heated independently to make the surface temperature consistent. The temperature uniformity of these two partition designs was compared. The result shows that the 9 regions design has higher temperature uniformity at both target temperatures of $-10^{\circ} \mathrm{C}$ and $+45^{\circ} \mathrm{C}$.
\end{abstract}

\section{Introduction}

The spacecraft payload in orbit provides certain requirements for the thermal control system. These requirements of spacecraft mainly include operating temperature range, temperature uniformity, temperature stability, etc. The temperature uniformity requirement is generally put forward in the form of temperature difference or temperature gradient, which is determined by the thermal deformation of materials. For the main mirror of a $1 \mathrm{~m}$ diameter solar telescope, the deviation of the mirror parabola is required to be less than $\lambda / 40$ $(\lambda=663 \mathrm{~nm})$, the focal distance difference is less than $0.15 \mathrm{~mm}$, and the displacement along the axis is less than $0.05 \mathrm{~mm}$. To maintain optical performance, the $3 \mathrm{~m}-$ diameter main mirror of the Hubble telescope should be kept at a constant temperature of $21.1^{\circ} \mathrm{C}$ and its temperature uniformity should be less than $0.1^{\circ} \mathrm{C}[1,2]$.

By exploring the space interference measurement task of the next generation space telescope (NGST), the requirements of optical system were proposed by NASA as follows: 1. The stability of the optical element position should be maintained at the nanoscale. 2. The relative position sensitivity of parliamentary optical elements is subnanometer. 3 . The torque of the optical element is controlled at the picometer level. Such high precision position and deformation requirements inevitably require the precise temperature control of scientific payload frame and precise support structure. Such as the temperature uniformity of the GRACE satellite is below $0.1{ }^{\circ} \mathrm{C}$, and $0.01{ }^{\circ} \mathrm{C}$ for the GOCE satellite [3].

Usually, the scientific payload is closely connected with the supporting structure. When the contact surface temperature is different, there is a heat conduction process between them. In this paper, a test platform with an effective test area of $600 \mathrm{~mm} \times 600 \mathrm{~mm}$ was taken as the research object, which was placed in a $7 \mathrm{~m}$ diameter and $6 \mathrm{~m}$ length thermal chamber with vacuum pressure of $1.3 \times 10^{-5} \mathrm{~Pa}$, background temperature of $-173^{\circ} \mathrm{C} \pm 5^{\circ} \mathrm{C}$. The temperature control target was $-10^{\circ} \mathrm{C}$ and $+45^{\circ} \mathrm{C}$. The realization of surface temperature uniformity was studied numerically.

\section{Thermal model}

The heat transfer process of a control volume is governed by three basic physical laws, namely mass conservation, momentum conservation and energy conservation. By solving these equations, the heat transfer process and temperature field distribution in the space can be obtained.

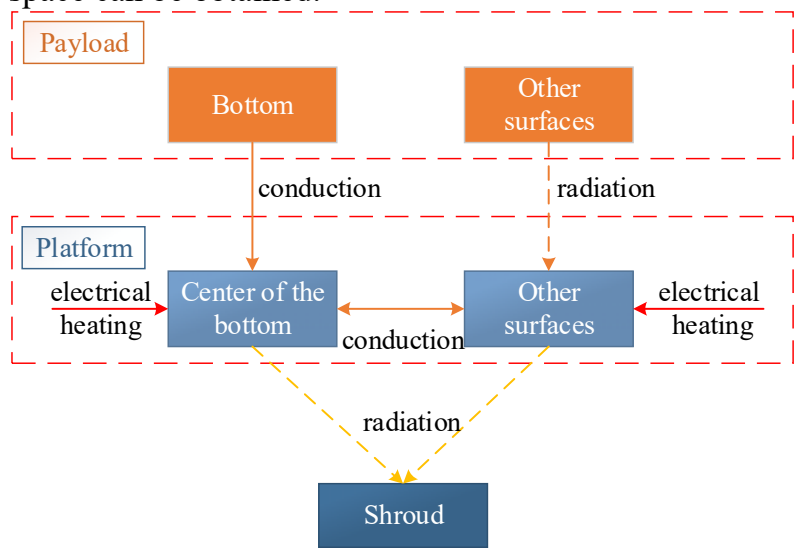

Fig. 1. Diagram of heat transfer process.

The heat transfer process between scientific payload, test platform and low temperature cold background is 
shown in Fig. 1: The heat generated by the scientific payload is transmitted to the central area of the test platform by conduction through the installation surface. The rest heat was transferred to other areas of the test platform through radiant heat transfer. All the heat is then radiated from the outside surface of the test platform to the low temperature cold background. Additionally, in order to keep the test platform at the target temperature, electric heating is required on the platform surface, which will eventually be taken away by radiation.

\section{Methodology}

In the space environment simulator where the high uniformity temperature simulation test platform is located, the gas pressure is lower than $1.3 \times 10^{-3} \mathrm{~Pa}$. So its flow and heat transfer are very weak, and can be ignored. Only the internal heat conduction conservation [4] of solid materials is considered, which can be simplified as follows.

$$
\frac{\partial}{\partial t}(\rho T)=\nabla \cdot\left(\frac{\lambda}{c_{p}} \operatorname{grad} T\right)
$$

In the formula, $\rho$ is the density. $T$ is the temperature. $\lambda$ is the thermal conductivity; $c_{\mathrm{p}}$ is constant pressure specific heat.

The Discrete Ordinates (DO) radiation model [5-8] was adopted for the radiation heat transfer between the surfaces. For a control volume, the radiation heat transfer equation is shown as follows:

$$
\begin{aligned}
\nabla \cdot(I(\mathbf{r}, \mathbf{s}) \mathbf{s})+ & \left(a+\sigma_{s}\right) I(\mathbf{r}, \mathbf{s})=a \mathbf{n}^{2} \frac{\sigma T^{4}}{\pi} \\
& +\frac{\sigma_{s}}{4 \pi} \int_{0}^{4 \pi} I\left(\mathbf{r}, \mathbf{s}^{\prime}\right) \Phi\left(\mathbf{s} \cdot \mathbf{s}^{\prime}\right) d \Omega
\end{aligned}
$$

where $\mathbf{r}$ is the position vector. $\mathbf{s}$ is the direction vector. $\mathbf{s}^{\prime}$ is the scattering direction vector. $a$ is the absorption coefficient. $\mathbf{n}$ is the refractive index. $\sigma_{\mathrm{s}}$ is the scattering coefficient. $\sigma$ is the Stefan-Boltzmann constant. $\mathrm{I}$ is the radiation intensity, which depends on position (r) and direction (s). $T$ is the local temperature. $\Phi$ is the phase function. $\Omega$ is the solid angle.

For gray diffuse radiation, the incident radiative heat flux $q_{\text {in }}$ at the wall is

$$
q_{i n}=\int_{\mathbf{s} \cdot \mathbf{n}>0} I_{i n} \mathbf{s} \cdot \mathbf{n} d \Omega
$$

The net radiative flux leaving the surface is given by

$$
q_{\text {out }}=(1-\varepsilon) q_{\text {in }}+n^{2} \varepsilon \sigma T^{4}
$$

The boundary intensity for all outgoing directions at the wall is given by

$$
I_{0}=\frac{q_{\text {out }}}{\pi}
$$

\section{Simulation and analysis}

In order to achieve the high uniformity of the platform surface temperature, the platform surface was divided into 5 or 9 regions where heated independently to make the surface temperature consistent. Furthermore, the result of uniform heating flow was compared with these two partition forms. The results were calculated by Fluent. The working pressure is $1 \times 10^{-5} \mathrm{~Pa}$. The temperature of the background is $-173{ }^{\circ} \mathrm{C}$. The background surface emissivity is 0.88 . The test platform surface emissivity is 0.8 . The calculation process is divided into three steps:

1) Set the temperature boundary condition of the simulator to isothermal boundary (e.g., $T=-10{ }^{\circ} \mathrm{C}$ ), after convergence, obtain the heating power $Q_{1} \sim Q_{\mathrm{n}}$ for each heating region.

2) According to the required heating power calculated in 1), the boundary condition of the heating regions is set as heat flux boundary with $Q_{1} \sim Q_{\mathrm{n}}$ respectively. The surface temperature distribution will be obtained to verify whether the temperature control requirements are met.

3) Optimize the heat flow on each surface to make the surface temperature of the platform consistent.

\subsection{Partition scheme}

The two partition schemes are shown in Fig. 2.

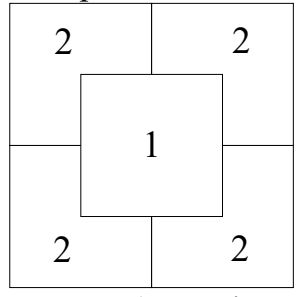

a) 5 regions

\begin{tabular}{|c|c|c|}
\hline 3 & 2 & 3 \\
\hline 2 & 1 & 2 \\
\hline 3 & 2 & 3 \\
\hline
\end{tabular}

b) 9 regions
Fig. 2. Partition schemes of the platform.

Partition scheme 1: The platform is divided into 5 regions for independent temperature control, as shown in Fig. 2 a). The effective test area named Part 1 is $300 \mathrm{~mm}$ $\times 300 \mathrm{~mm}$ in the centre of the platform. The surrounding area is divided into 4 symmetrical L-shaped areas named Part 2 with equal heat flow.

Partition scheme 2: Based on the Partition scheme 1, the platform is further divided into 9 regions for independent temperature control, as shown in Fig. 2 b). The shape of the middle area remains the same and is named as Part 1. The surrounding areas are more specifically divided into the marginal areas Part 2 and the corner areas Part 3.

\subsection{Simulation results}

\begin{tabular}{|c|c|c|c|}
\hline \multirow{2}{*}{ Regions } & \multicolumn{3}{|c|}{ Heat flux $\left(W / m^{2}\right)$} \\
\hline & Uniform & Partition & Partition \\
\hline
\end{tabular}

\subsubsection{Target temperature of $-10^{\circ} \mathrm{C}$}

When the platform temperature is stable to $-10{ }^{\circ} \mathrm{C}$, the heat flux required for each partition is shown in Table 1.

Table 1. The heat flux required for Target temperature of $10^{\circ} \mathrm{C}$. 


\begin{tabular}{cccc}
\hline & heating & scheme 1 & scheme 2 \\
\hline Part 1 & 222 & 218.56 & 218.56 \\
\hline Part 2 & - & 230.70 & 227.72 \\
\hline Part 3 & - & - & 237.85 \\
\hline
\end{tabular}

If the platform surface heat flow was kept at a uniform value (like $222 \mathrm{~W} / \mathrm{m}^{2}$ in this case), the bottom surface temperature of the test platform was from $-25^{\circ} \mathrm{C}$ $\sim 10{ }^{\circ} \mathrm{C}$ as shown in Fig. 3 a), for the clod background temperature of $100 \mathrm{~K}\left(-173.15{ }^{\circ} \mathrm{C}\right)$. The temperature range of the effective test area with $300 \mathrm{~mm} \times 300 \mathrm{~mm}$ was from $-10.75^{\circ} \mathrm{C}$ to $-10{ }^{\circ} \mathrm{C}$ as shown in Fig. b). It is indicated that the uniform heating method cannot meet the temperature uniformity requirement of $\pm 0.025^{\circ} \mathrm{C}$.
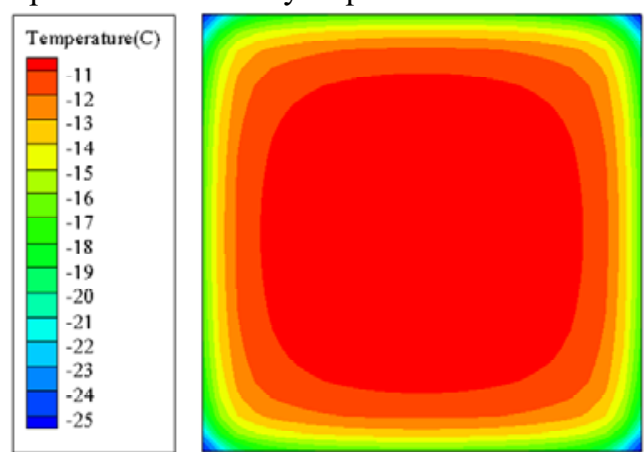

a) Bottom of the platform

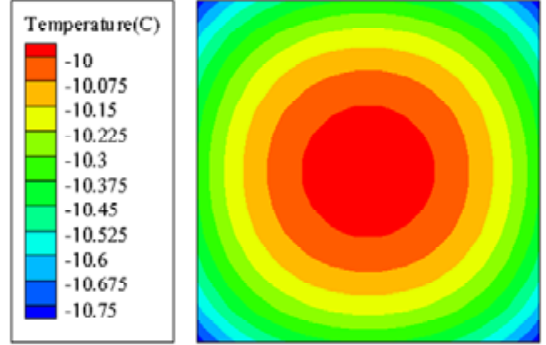

b) Effective test

Fig. 3. Surface temperature of uniform heating for $-10^{\circ} \mathrm{C}$.

The surface temperature distribution of the platform surface is shown in Fig. 4 a) under the heat flux condition of Partition scheme 1 , the platform surface temperature was $-10.26{ }^{\circ} \mathrm{C} \sim 9.85{ }^{\circ} \mathrm{C}$. The temperature uniformity area at $\pm 0.025^{\circ} \mathrm{C}$ is shown in Fig. 4 b) with a surface temperature range from $-10{ }^{\circ} \mathrm{C}$ to $-9.95{ }^{\circ} \mathrm{C}$. The uniform temperature area was a circular area with a diameter of $478 \mathrm{~mm}$.

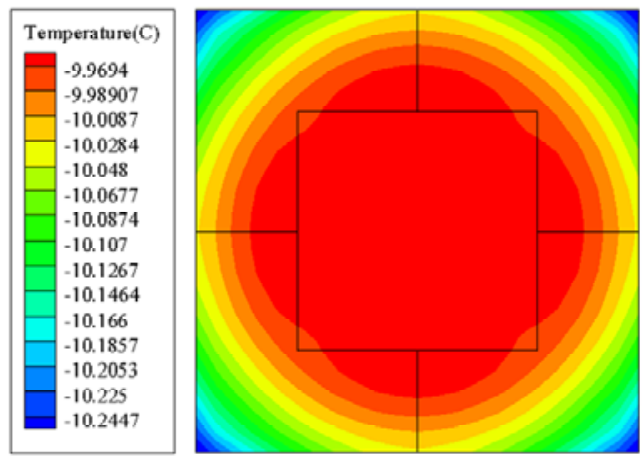

a) Bottom of the platform

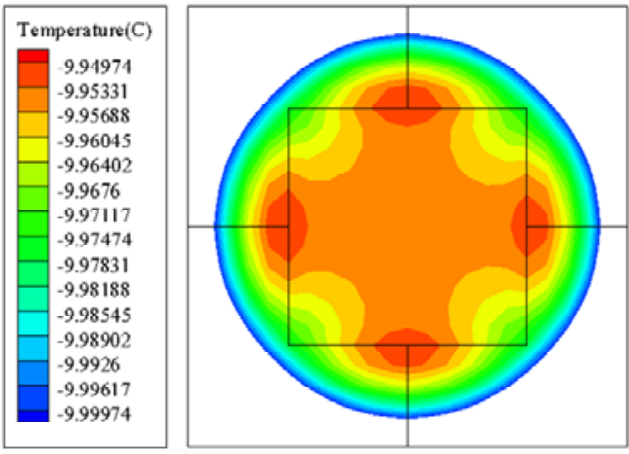

b) Temperature uniformity area

Fig. 4. Surface temperature of Partition scheme 1 for $-10^{\circ} \mathrm{C}$.

The surface temperature distribution of the platform surface is shown in Fig. 5 a) under the heat flux condition of Partition scheme 2, the platform surface temperature was $-10.23^{\circ} \mathrm{C} \sim-9.87^{\circ} \mathrm{C}$. The temperature uniformity area at $\pm 0.025^{\circ} \mathrm{C}$ is shown in Fig. 5 b) with a surface temperature range from $-10.02{ }^{\circ} \mathrm{C}$ to $-9.97{ }^{\circ} \mathrm{C}$. The uniform temperature area was $467 \mathrm{~mm} \times 467 \mathrm{~mm}$.
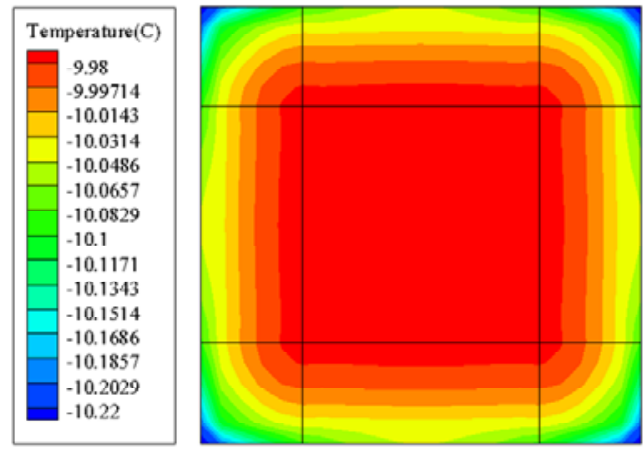

a) Bottom of the platform

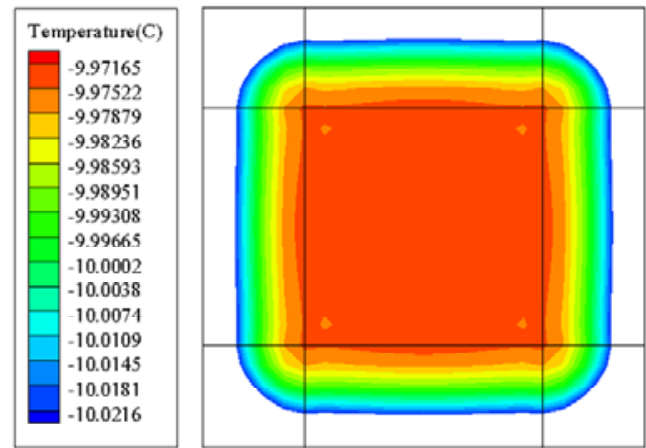

b) Temperature uniformity area

Fig. 5. Surface temperature of Partition scheme 2 for $-10^{\circ} \mathrm{C}$.

\subsubsection{Target temperature of $+45^{\circ} \mathrm{C}$}

When the platform temperature is stable to $45{ }^{\circ} \mathrm{C}$, the heat flux required for each partition is shown in Table 2.

Table 2. The heat flux required for Target temperature of $+45^{\circ} \mathrm{C}$.

\begin{tabular}{llll}
\hline \multirow{2}{*}{ Regions } & \multicolumn{3}{c}{ Heat flux $\left(\mathrm{W} / \mathrm{m}^{2}\right)$} \\
\cline { 2 - 4 } & Uniform & Partition & Partition \\
\hline
\end{tabular}




\begin{tabular}{cccc}
\hline & heating & scheme 1 & scheme 2 \\
\hline Part 1 & 470 & 466.39 & 466.39 \\
\hline Part 2 & - & 488.29 & 482.99 \\
\hline Part 3 & - & - & 500.99 \\
\hline
\end{tabular}

When the platform surface heat flow was kept at $470 \mathrm{~W} / \mathrm{m}^{2}$, the bottom surface temperature of the test platform was $26^{\circ} \mathrm{C} \sim 46{ }^{\circ} \mathrm{C}$ as shown in Fig. 6 a). The temperature range of the effective test area was from $44.6{ }^{\circ} \mathrm{C}$ to $45.6{ }^{\circ} \mathrm{C}$ as shown in Fig. $6 \mathrm{~b}$ ). The uniform heating method cannot meet the temperature uniformity requirement of $\pm 0.025^{\circ} \mathrm{C}$ for target temperature of $+45^{\circ} \mathrm{C}$ neither.

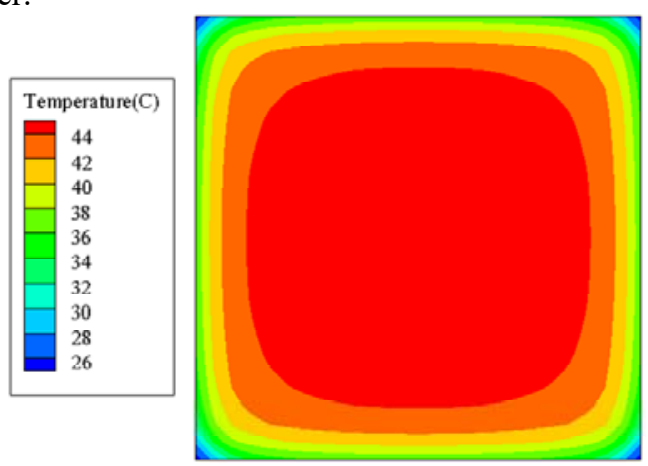

a) Bottom of the platform

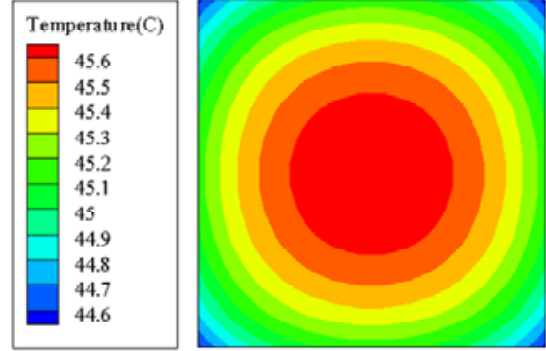

b) Effective test area

Fig. 6. Surface temperature of uniform heating for $+45^{\circ} \mathrm{C}$.

The surface temperature distribution of the platform surface is shown in Fig. 7 a) for the target temperature of $+45^{\circ} \mathrm{C}$ under Partition scheme 1 condition, the platform surface temperature was $+44.53{ }^{\circ} \mathrm{C} \sim+45.09{ }^{\circ} \mathrm{C}$. The temperature uniformity area at $\pm 0.025^{\circ} \mathrm{C}$ is shown in Fig. $7 \mathrm{~b})$ with a surface temperature range from $+45.04^{\circ} \mathrm{C}$ to $+45.09{ }^{\circ} \mathrm{C}$. The uniform temperature area was a circular area with a diameter of $430 \mathrm{~mm}$.
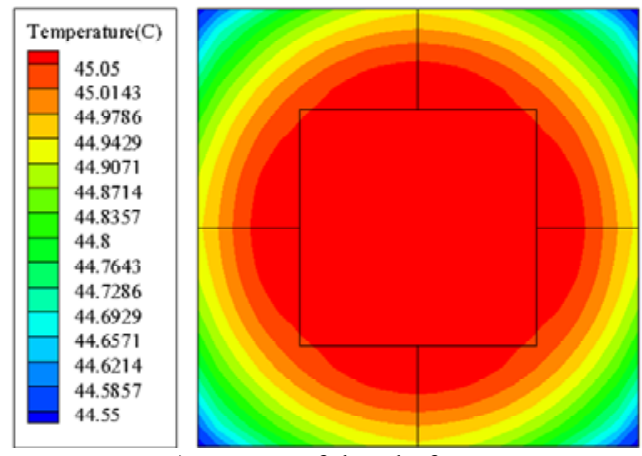

a) Bottom of the platform

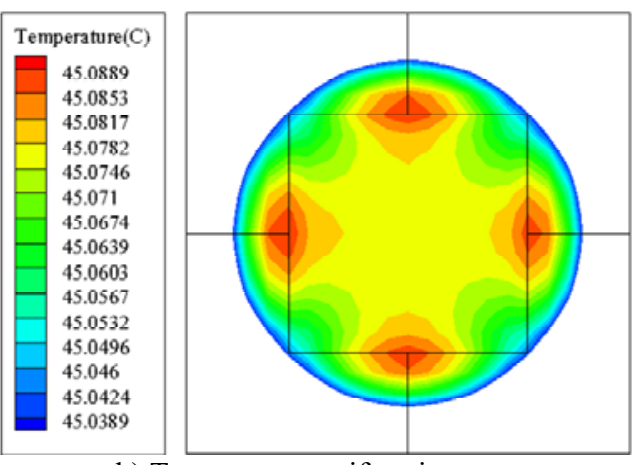

b) Temperature uniformity area

Fig. 7. Surface temperature of Partition scheme 1 for $+45^{\circ} \mathrm{C}$.

Under the heat flux condition of Partition scheme 2, the platform surface temperature was $+44.58{ }^{\circ} \mathrm{C} \sim$ $+45.05{ }^{\circ} \mathrm{C}$ as shown in Fig. 8 a). The temperature uniformity area at $\pm 0.025^{\circ} \mathrm{C}$ shown in Fig. 8 b) had a surface temperature range from $+45^{\circ} \mathrm{C}$ to $+45.05^{\circ} \mathrm{C}$. The uniform temperature area was $420 \mathrm{~mm} \times 420 \mathrm{~mm}$.
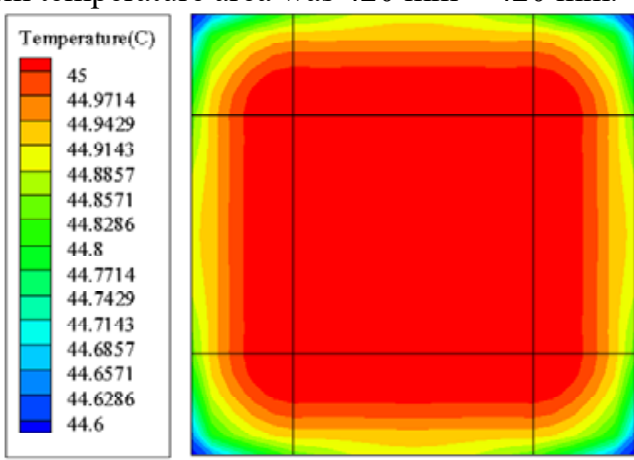

a) Bottom of the platform

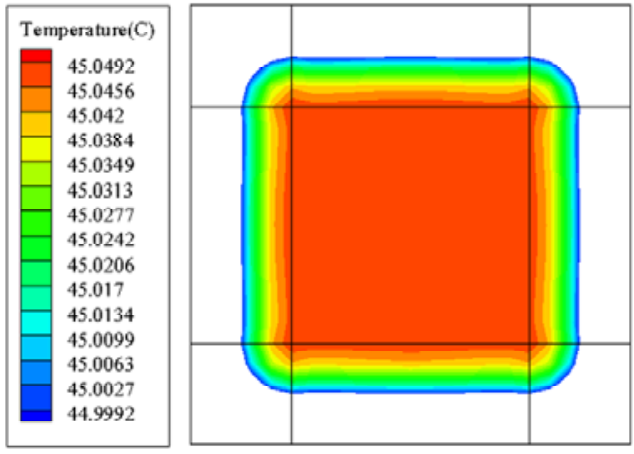

b) Temperature uniformity area

Fig. 8. Surface temperature of Partition scheme 2 for $+45^{\circ} \mathrm{C}$.

\subsection{Discussion}

\subsubsection{Temperature uniformity}

As shown in Fig. 3 and Fig. 6, the uniform heating method is unable to make the temperature difference within $\pm 0.025^{\circ} \mathrm{C}$ in the effective test area with $300 \mathrm{~mm} \times$ $300 \mathrm{~mm}$ under target temperature of -10 and $45^{\circ} \mathrm{C}$. However, both partition methods can achieve temperature uniformity. 


\subsubsection{Temperature uniform region}

The temperature uniform region of partition scheme 1 is circular and that of Partition scheme 2 is a square. The area of the temperature uniform region is calculated as shown in Table 3. It can be seen from Table 3 that the area of temperature uniform region for partition scheme 2 is larger than that of scheme 1. Moreover, the shape of temperature uniform region for scheme 2 is consistent with the shape of the payload. Therefore, the 9 partition regions design is more appropriate.

Table 3. Area of the temperature uniform region.

\begin{tabular}{cccc}
\hline $\begin{array}{c}\text { Target } \\
\text { temperature } \\
\left({ }^{\circ} \mathrm{C}\right)\end{array}$ & $\begin{array}{c}\text { Partition } \\
\text { scheme }\end{array}$ & Size $\mathbf{( m )}$ & $\begin{array}{c}\text { Area } \\
\left(\mathbf{m}^{\mathbf{2}}\right)\end{array}$ \\
\hline \multirow{2}{*}{-10} & 1 & $\phi 0.478$ & 0.1795 \\
\cline { 2 - 4 } & 2 & $0.467 \times 0.467$ & 0.2181 \\
\hline \multirow{2}{*}{45} & 1 & $\phi 0.43$ & 0.1452 \\
\cline { 2 - 4 } & 2 & $0.42 \times 0.42$ & 0.1764 \\
\hline
\end{tabular}

\section{Conclusion}

The surface temperature uniformity of a test platform with an effective test area of $600 \mathrm{~mm} \times 600 \mathrm{~mm}$ was numerically studied in this paper. The conductive heat transfer model for the test platform and DUT installed on the surface was established, as well as the radiative heat transfer model from the platform surface to the background temperature. The surface uniformity of the test platform at the target temperature of $-10,45^{\circ} \mathrm{C}$ is analysed under two partition schemes. The result shows that the 9 regions design has higher temperature uniformity.

\section{References}

1. Alson E H. Finite element methods for evaluating optical system performance. SPIE, 518: 145 - 149, (1984).

2. Olivieri M, Pieri S, Romoli A. Analysis of defocusing thermal effects in optical systems. SPIE, 2774: 283 - 292, (1996).

3. Zurmehly G E, Hookman R A. Thermal and structure analysis of the GOES. SPIE, 1532: 170 176, (1991).

4. Kaviany M. Principles of heat transfer. (New York: John Wiley and Sons, Inc., 2002).

5. E. H. Chui and G. D. Raithby. Computation of Radiant Heat Transfer on a Non-Orthogonal Mesh Using the Finite-Volume Method. Numerical Heat Transfer, Part B, 23:269-288, (1993).

6. G. D. Raithby and E. H. Chui. A Finite-Volume Method for Predicting a Radiant Heat Transfer in Enclosures with Participating Media. J. Heat Transfer, 112:415-423, (1990).

7. J. Y. Murthy and S. R. Mathur. A Finite Volume Method For Radiative Heat Transfer Using Unstructured Meshes. AIAA-98-0860, (1998).

8. S. R. Mathur and J. Y. Murthy. Coupled ordinates method for multigrid acceleration of radiation calculations. J. of Thermophysics and Heat Transfer, 13(4):467-473, (1999). 